\title{
Lytic Cell Death in Specific Microglial Subsets Is Required for Preventing Atypical Behavior in Mice
}

\author{
Hsiu-Chun Chuang, ${ }^{1 *}$ Eva K. Nichols, ${ }^{1 *}$ Isabella Rauch, ${ }^{1,2}$ Wei-Cheng Chang, ${ }^{1}$ Patrick M. Lin, ${ }^{1}$ \\ Rhea Misra, ${ }^{1}$ Maiko Kitaoka, ${ }^{1}$ Russell E. Vance, ${ }^{1,2}$ and ${ }^{-K}$ Kaoru Saijo ${ }^{1,3}$
}

https://doi.org/10.1523/ENEURO.0342-20.2020

${ }^{1}$ Division of Immunology and Pathogenesis, Department of Molecular and Cell Biology, University of California, Berkeley, Berkeley, CA 94720-3200, 2 Howard Hughes Medical Institute, University of California, Berkeley, Berkeley, CA 94720-3200, and ${ }^{3}$ Helen Wills Neuroscience Institute, University of California, Berkeley, Berkeley, CA 94720-3200

\begin{abstract}
Microglial cells are known to contribute to brain development and behaviors, but the mechanisms behind such functions are not fully understood. Here, we show that mice deficient in inflammasome regulators, including caspase-1 (Casp1), NLR family pyrin domain containing 3 (NIrp3), IL-1 receptor (II-1r), and gasdermin D $(G s d m d)$, exhibit behavior abnormalities characterized by hyperactivity and low anxiety levels. Furthermore, we found that expression of Casp 1 in $\mathrm{CX} 3 \mathrm{CR} 1^{+}$myeloid cells, which includes microglia, is required for preventing these abnormal behaviors. Through tissue clearing and 3D imaging, we discovered that small numbers of Cx3cr1-GFP ${ }^{+}$fetal microglial cells formed clusters and underwent lytic cell death in the primitive thalamus and striatum between embryonic day (E)12.5 and E14.5. This lytic cell death was diminished in Casp1-deficient mice. Further analysis of the microglial clusters showed the presence of Pax6 ${ }^{+}$neural progenitor cells (NPCs); thus, we hypothesized that microglial lytic cell death is important for proper neuronal development. Indeed, increased numbers of neurons were observed in the thalamic subset in adult Casp $1^{-1-}$ brains. Finally, injection of drug inhibitors of NLRP3 and CASP1 into wild-type (WT) pregnant mice from E12.5 to E14.5, the period when lytic cell death was detected, was sufficient to induce atypical behaviors in offspring. Taken together, our data suggests that the inflammasome cascade in microglia is important for regulating neuronal development and normal behaviors, and that genetic or pharmacological inhibition of this pathway can induce atypical behaviors in mice.
\end{abstract}

Key words: behavior; cell death; microglia

\section{Significance Statement}

Microglia support brain development, but the underlying mechanisms are not fully understood. Here, we show that mice deficient for inflammasome cascade protein genes, including NLR family pyrin domain containing 3 (NIrp3), caspase-1 (Casp1), IL-1 receptor (II-1r), and gasdermin D (Gsdmd), develop behavior abnormalities characterized by hyperactivity and low anxiety. Lytic cell death occurs downstream of inflammasomes and was observed to appear in microglia in spatiotemporal and Casp1-dependent manners. Microglial death may be important for the proper differentiation of neural progenitor cells (NPCs), as indicated by increased neuron numbers in specific regions of the brain in Casp1-deficient mice. Importantly, injection of NLRP3 and CASP1 inhibitors into pregnant mothers during this lytic death window resulted in offspring with behavior abnormalities. Overall, the death of discrete microglial subsets may be essential for proper NPC development and normal behaviors.

Received August 9, 2020; accepted December 17, 2020; First published January 4, 2021.

The authors declare no competing financial interests.
Author contributions: H.-C.C., E.K.N., and K.S. designed research; H.-C.C., E.K.N., W.-C.C., P.M.L., R.M., and M.K. performed research; I.R. and R.E.V. contributed unpublished reagents/analytic tools; H.-C.C., E.K.N., and K.S. analyzed data; K.S. wrote the paper. 


\section{Introduction}

Normal brain development is a series of complex events that can be affected by either genetic or environmental factors. Disruptions in these events can result in neurodevelopmental disorders, such as attention-deficit/hyperactivity disorder (ADHD), autism, and intellectual disabilities characterized by atypical behaviors. Interestingly, cell death by apoptosis has been shown to be essential for normal brain development by controlling the number of neurons in the brain and by helping to establish functional circuits (Yoshida et al., 1998; Yamaguchi and Miura, 2015; Fricker et al., 2018); however, it has not yet been reported whether other types of cell death (lytic cell death such as pyroptosis) are also important for regulating these developmental processes.

Microglial cells are resident innate immune cells in the central nervous system that protect the brain from infection and injury; however, recent studies indicate that they are also crucial for brain development and normal functions (Saijo and Glass, 2011; Ransohoff and El Khoury, 2015; Wolf et al., 2017). For example, a patient with a homozygous mutation in the CSF1R gene, which plays essential roles in microglial development, lacked microglia and showed severe defects in brain development (Oosterhof et al., 2019). It has also been reported that microglia-mediated synaptic regulation plays crucial roles in the establishment and maintenance of neural circuits (Paolicelli et al., 2011; Hong et al., 2016). However, the molecular mechanisms behind how microglia shape these circuits and affect their corresponding behaviors are not well understood.

Inflammasomes are cytosolic sensors for a variety of pathogenic and noxious stimuli (Rathinam and Fitzgerald, 2016). In the brain, previous reports suggest that inflammasomes are differentially expressed in different cell types. For example, NLR family pyrin domain containing 1 (NLRP1) and AIM2 were detected in neurons, while NLRP2 and NLRP3 were found in astrocytes (Mamik and Power, 2017; Heneka et al., 2018; Voet et al., 2019). Microglia were also observed to express various

E.K.N. was supported by the Chancellor's Fellowship, Elizabeth Roboz Einstein Fellowship, and University of California dissertation year fellowship. I.R. was supported by the Austrian Science Fund (the Erwin Schrödinger Fellowship). M.K. was supported by the Department of Molecular and Cell Biology, Training Grant 4T32GM07232-40 and National Science Foundation, Graduate Research Fellowship Program. R.E.V. is an Howard Hughes Medical Institute Investigator and is supported by National Institutes of Health (NIH) Grants Al075039 and Al063302. K.S. is supported by the NIH Grant R01HD092093, a Searle Scholarship, a Hellman Fellowship, and a Pew Scholarship.

${ }^{*}$ H.-C.C. and E.K.N. contributed equally to this work.

I. Rauch's present address: Department of Molecular Microbiology and Immunology, Oregon Health and Science University, Portland, OR 97239.

Acknowledgements: We thank the Saijo lab for discussion and E. Robey for critical reading of this manuscript. We also thank $\mathrm{H}$. Aaron and J. Y. Lee for imaging analysis help and A. Sullivan (Obrizus Communications) for editing.

Correspondence should be addressed to Kaoru Saijo at ksaijo@ berkeley.edu.

https://doi.org/10.1523/ENEURO.0342-20.2020

Copyright @ 2021 Chuang et al.

This is an open-access article distributed under the terms of the Creative Commons Attribution 4.0 International license, which permits unrestricted use, distribution and reproduction in any medium provided that the original work is properly attributed. inflammasomes, particularly NLRP1, NLRP3, and NLRC4 were highly expressed in this cell type (Walsh et al., 2014; Mamik and Power, 2017; Heneka et al., 2018; Voet et al., 2019). Activated inflammasomes serve as platforms that initiate the cleavage of pro-caspase-1 (CASP1) to CASP1, which then cleaves pro-IL-1 $\beta$ to generate a mature cytokine. CASP1 also cleaves gasdermin D (GSDMD), which is required for subsequent IL-1 $\beta$ secretion, lytic cell death (pyroptosis), and inflammation (Kayagaki et al., 2015; Shi et al., 2015; Extended Data Fig. 1-1A).

The importance of the inflammasome pathway in protecting the host from infection and injury is well established (Broz and Dixit, 2016). In addition to being a sentinel, it has also been reported that the inflammasome protein NLRP3 in microglia recognizes amyloid- $\beta$ peptide and induces an inflammatory response that contributes to the pathogenesis of Alzheimer's disease (Heneka et al., 2013). The idea that NLRP3 plays a role in Alzheimer's disease has been further supported by recent evidence indicating that NLRP3 regulates tau phosphorylation and aggregation (Ising et al., 2019). Thus, inflammasomes can be involved in the onset and progression of neurologic disorders; however, their role in early brain development is not understood or expected.

Previous literature has shown that mice deficient for interleukin-1 receptor (II-1r) exhibit hyperactivity and low anxiety levels (Murray et al., 2013). Since mature IL-1 $\beta$ is the product of inflammasome activation, we hypothesized that this pathway might be required for normal brain development and behavior. To test our hypothesis, we ran a panel of behavior assays (Table 1) using mice deficient for factors of the inflammasome cascade and found that they exhibited specific behavior abnormalities. Moreover, during normal development, we observed that lytic cell death occurred in subsets of $\mathrm{C} \times 3 \mathrm{cr} 1-\mathrm{GFP}^{+}$brain parenchymal microglial cells, particularly those located in the primitive thalamus and striatum, but this death was notably absent in mice lacking Casp1. Furthermore, administration of inhibitors of NLRP3 and CASP1 to wild-type (WT) pregnant female mice at specific gestational days induced behavior abnormalities in their offspring that were similar to those observed in the knock-out mice. Overall, our data suggests that the inflammasome cascade mediated by NIrp3, Casp1, II-1r, and Gsdmd in microglia is important for normal brain development and for preventing abnormal behaviors in mice.

\section{Materials and Methods}

\section{Animals}

Both male and female mice (aged two to four months old) were used in this study. All animals were maintained in specific pathogen-free conditions under a 12/12 h light/ dark cycle (7 A.M. to 7 P.M.) and were given a standard chow diet and water ad libitum. WT C57BL/6J mice were purchased from The Jackson Laboratory. Casp $1^{-1-}$ Casp $11^{-/-}$mice were on the C57BL/6J background and were kindly provided by $A$. van der Velden and $M$. Starnbach (van der Velden et al., 2003). Casp1 ${ }^{-/-}$, iCasp1, NIrp3 ${ }^{-1-}$, and Gsdmd ${ }^{-/-}$mice on the C57BL/6J background were generously provided by R. E. Vance 
Table 1: Behavior assays

\begin{tabular}{ll}
\hline Behavior & Assay \\
\hline Hyperactivity & Open field assay (total distance they moved) \\
Anxiety & Elevated plus maze assay \\
Attention & 5-CSRTT assay \\
\hline
\end{tabular}

The behavior assays used in this study are shown.

(Rauch et al., 2017). Tg(Cx3cr1-cre)MW126Gsat mice were generated by the Heintz laboratory at The Rockefeller University and were purchased from MMRRC (University of California Davis). We backcrossed the $\mathrm{Tg}(\mathrm{C} \times 3 \mathrm{cr} 1$-cre) MW126Gsat mice to C57BL/6J mice $>10$ times before crossing with other strains. $I I-1 r^{-1-}$ and $C \times 3 c r 1^{\text {GFP/GFP }}$ mice were on the C57BL6/J background and were purchased from The Jackson Laboratory. To normalize gut microbiota, all animals were cohoused in mixed-genotype groups of three to five mice per cage on weaning. If cohousing was not done, their bedding was mixed regularly to normalize the microenvironment. All experiments were approved by the Animal Care and Use Committee and were performed under the institutional guidelines.

\section{Behavior assays}

Open field assay

For the experiments with Casp $1^{-1-}$ mice, both male and female mice were used, as indicated. For the experiments with II-1r ${ }^{-1-}$, Gsdmd ${ }^{-/-}, \mathrm{NIrp3}^{-1-}$, and iCasp1 (reexpression and their controls) mice, only male mice were used. We also used only male offspring from inhibitor-injected mothers for this assay. Mice were individually placed in the center of a plastic box $(22 \times 42.5 \times 21 \mathrm{~cm})$ for $1 \mathrm{~h}$ and were allowed to freely explore the arena. The data from the first $30 \mathrm{~min}$ of exploration were used in our analysis (Komada et al., 2008; Jiang et al., 2010; Chung et al., 2011). Animal movement was monitored by computerized photobeam using the MotorMonitor SmartFrame System (Kinder Scientific).

\section{Elevated plus maze assay}

We used both male and female Casp $1^{-1-}$ mice (as indi-

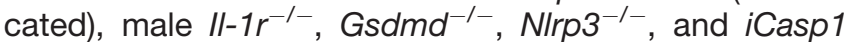
(re-expression and their controls) mice, as well as male offspring from inhibitor-injected mothers for this assay. Mice were individually placed in the center of a platform $(5 \times 5 \mathrm{~cm})$ of a maze that consisted of two open and two closed arms $(30 \times 5 \mathrm{~cm})$ that were elevated $30 \mathrm{~cm}$ from the floor. Mice were allowed to freely explore the maze for 10 min (Lin and Hsueh, 2014; Nakajima et al., 2019; Shieh and Yang, 2019) and the Smart Video Tracking System (Panlab) was used to determine the time spent in the open and closed arms, as well as the center, during the test. The number of entries into each arm was also analyzed.

\section{Five-choice serial reaction time task (5-CSRTT) assay}

Casp $1^{-1-}$ and WT male mice were used for this assay. The procedures used in this task were as previously described with modifications (Sanchez-Roige et al., 2012). A Plexiglas operator chamber $(19 \times 22 \times 24 \mathrm{~cm})$ with five response apertures and a food magazine was automatically controlled by the software (Packwin, Panlab). The procedure consisted of the pretraining, magazine training, and 5 -CSRTT training phases. Before the test and then throughout the entire experiment, the mice were food-restricted $(1.8-2 \mathrm{~g} / \mathrm{d})$. On the first day of food restriction, the mice were introduced to some reward pellets (TestDiet 14-mg sugar pellets) to familiarize them with their taste. During the pretraining phase, mice were habituated to the chamber with five reward pellets in the food magazine and one reward pellet in each of the five apertures being placed for each operant chamber. The magazine light and all five stimulus lights remained illuminated for the duration of the session. The mice were individually placed in the chamber and allowed to freely explore for $10 \mathrm{~min}$. The habituation session was repeated until all the pellets were consumed. On the day of magazine training, the mice were placed in the chamber for a 4-min period of free exploration, followed by all five stimulus lights being switched on throughout the remainder of the session. After a random nose-poke response was made in one of the five apertures, the mouse was given one pellet in the food magazine. Once the mice earned 20 pellets, they commenced the 5-CSRTT training, which graduates through increasingly challenging stages (stages 1-6) on a schedule of progressively decreasing stimulus duration (SD) and increasing intertrial intervals (ITIs). The percentage of accuracy was calculated as [(number of correct trials/(number of correct and incorrect trials)) $\times 100]$. The number of days taken to achieve the criteria for stage 6 (accuracy $>75 \%$, correct trials $>20$ ) was recorded to indicate the attention performance. After meeting the criteria of stage 6 for at least two consecutive days, mice were moved forward in the testing schedule in which the variable ITI $(5,8.75$, and $12.5 \mathrm{~s})$ was randomly presented with an SD of $1.25 \mathrm{~s}$. The percent accuracy was also calculated in this testing.

\section{PI injection and tissue clearing}

A total volume of $100 \mu$ l of propidium iodide (PI; $1.0 \mathrm{mg} /$ $\mathrm{ml}$ ) solution was intravenously injected into pregnant female mice at specific gestational dates. After 10-30 min of incubation, the mice were killed. Intact fetal bodies were recovered, fixed, and subjected to the CUBIC tissue clearing method (Susaki et al., 2014).

\section{Light sheet fluorescence microscopy (LSFM) and analysis}

We used male embryos that resulted from crossing WT or Casp $1^{-1-}$ mice with Cx3cr1-GFP mice for this assay. LSFM was performed using the Zeiss Lightsheet Z.1 system and $5 \times$ objective set (EC Plan-Neofluar $5 \times / 0.16$ detection and LSFM $5 \times / 0.1$ illumination lens) at $0.36 \times$ zoom. CUBIC R2 solution was used as the refractive index-matched solution. Coronal acquisitions captured the entirety of the embryonic forebrain ( $\sim 620 \mathrm{Z}$ slices) with voxel sizes approximately $x=2.13 \mu \mathrm{m}, y=2.13 \mu \mathrm{m}$, and $z=6.16 \mu \mathrm{m}$. Imaging data were processed and analyzed by Imaris 9.1 .0 software (Bitplane). 


\section{Immunofluorescence staining}

We used male WT and Casp $1^{-1-}$ embryos and adult brains for this assay. Intact tissues were fixed in 4\% paraformaldehyde (PFA) in PBS overnight at $4^{\circ} \mathrm{C}$ and underwent complete sucrose gradient up to $30 \% \mathrm{wt} / \mathrm{vol}$ in PBS. Tissues were next embedded in a 1:1 mix of TissueTek O.C.T. compound with $30 \%$ sucrose in PBS and sectioned $(40-\mu \mathrm{m}$ sections) with a cryostat. Slides were dried and permeabilized with $0.1 \%$ Triton X-100 in PBS. After blocking, sections were incubated with primary antibodies (see Table 2) followed by secondary antibodies.

\section{Drug administration to mice}

Pregnant C57BL/6 mice were given three intraperitoneal injections of either VX-765 $(50 \mathrm{mg} / \mathrm{kg} / \mathrm{d}$, caspase- 1 inhibitor, InvivoGen), MCC950 (50 mg/kg/d, NLRP3-inflammasome inhibitor, InvivoGen), or saline as vehicle. Drugs were injected once per day starting on embryonic day (E)12.5 until E14.5. Behavioral assays were performed on the male offspring when they were eight weeks old.

\section{RNA extraction and RT-qPCR}

Total RNA was isolated using the DirectZol kit (Zymo Research). RTs were performed using SuperScript III (ThermoFisher) and qPCR was performed using the KAPA SYBR Green Fast qPCR kit by following the manufacturer's protocols.

Primers used in this assay were as follows: Hprt: $\mathrm{F} 5^{\prime}-$ TCAGTCAACGGGGGACATAAA-3' and R $5^{\prime}$-GGGGCTGT ACTGCTTAACCAG-3'; Casp1: F 5'-TGGGACCCTCAAGTT TTGCCC-3' and R 5'-GGCAAGACGTGTACGAGTGGTT-3'; Nirp3: F 5'-CTTTGCTGCGATCAACAGGCG-3' and R 5'TCAAGGCTGTCCTCCTGGCATA-3'; Cd200: F 5'-TCACTT GCTCTGCGACTGCC-3' and R 5'-GGGGTCTTTGACCCG GAGGA-3'; and Celf4: F 5'-CAAGGAGCGCACAATGCGAC3', R 5'-ATGAGGGCTGCTTGCTGCTG-3'.

\section{Nissl staining and stereology}

Three adult age-matched WT and Casp $1^{-1-}$ male mice underwent transcardial perfusion with PBS and $4 \%$ PFA in PBS and postfixation overnight in 4\% PFA in PBS. Brains were embedded in O.C.T. compound (Sakura VWR) before serial sectioning at $40 \mu \mathrm{m}$ in a cryostat. For Nissl staining, sections were stained in Cresyl violet solution $(0.3 \% \mathrm{wt} / \mathrm{vol}$ Cresyl violet acetate in water plus $0.3 \%$ glacial acetic acid v/v; Sigma C-1791 and 537020) for $45 \mathrm{~min}$. Sections were rinsed in $\mathrm{dd}_{2} \mathrm{O}$ and subjected to an ethanol dehydration series (1-min steps; $70 \%, 95 \%$, $100 \% \mathrm{EtOH}$ ) before clearing in xylenes for 3 min (Sigma 214736). Sections were mounted in Permount and dried for 24-48 $\mathrm{h}$ before imaging.

The Cavalieri volume estimation method (MicroBrightField) was used to estimate the volume of the thalamus of three adult age-matched WT and Casp $1^{-1-}$ mouse brains (from approximately bregma $-1 \mathrm{~mm}$ to $+4 \mathrm{~mm}$ ). Nissl-stained sections $(40 \mu \mathrm{m})$ were visualized using the brightfield setting on a BX51 microscope (Olympus) connected to a computer running Stereo Investigator 11.03 software (MicroBrightField). Afterwards, markers were placed (using a grid spacing of
Table 2: Information on primary antibodies

\begin{tabular}{llll}
\hline Name & Vendor & Catalog \# & Dilution \\
\hline NeuN & Millipore Sigma & ABN78 & $1: 300$ \\
Parvalbumin & Millipore Sigma & P3088 & $1: 1000$ \\
Iba1 & Thermo Fisher & PA5-18039 & $1: 250$ \\
Pax6 & Eurogentec & PRB-278P-100 & $1: 100$
\end{tabular}

The information on primary antibodies used in this study is shown.

$50 \mu \mathrm{m}$ and a section evaluation interval of 6) over these regions for a total of 11 slices throughout the thalamus. Contours were drawn according to regions defined by the Allen Brain Atlas. Total volumes were then determined using the built-in software estimator. All volume estimations except for one possessed a Gundersen coefficient of error $<0.10$.

\section{Statistical analysis}

Data are shown as averages with error bars indicating SEM. Sample sizes were calculated based on the Boston University IACUC spread sheet. Statistical analysis was performed using Prism 7 (GraphPad) software. We used the Student's $t$ test to compare two different groups, and we used the one-way ANOVA with post hoc tests (Bartlett's test and Brown-Forsythe test) to compare three different groups. In addition to one-way ANOVA, Tukey's multiple comparison tests were performed to show the individual $p$ values. The data were provided to the figure legends. The Fisher's exact test was used to analyze contingency tables to determine the probability that the distributions were not because of chance. Table 3 shows the $t$ values, df, and $p$ values for the Student's $t$ tests, and Table 4 shows the sum-of-squares (SS), df, the mean squares (MS), $F$ ratios, and $p$ values for the oneway ANOVAs between columns, within columns, and total for the indicated figures; $p<0.05$ was considered to be statistically significant.

Table 3: Information for Student's $t$ tests

\begin{tabular}{llll}
\hline Figure & $t$ value & df & $p$ value \\
\hline Fig. 1A & 3.142 & 21 & 0.0049 \\
Fig. 1B & 3.371 & 21 & 0.0029 \\
Fig. 1E & 2.520 & 17 & 0.0220 \\
Fig. 1F & 2.776 & 17 & 0.0130 \\
Fig. 4C & 3.694 & 4 & 0.0209 \\
Fig. 4E & 0.336 & 4 & 0.7533 \\
Extended Data Fig. 1-1B & 3.371 & 21 & 0.0029 \\
Extended Data Fig. 1-1C & 4.425 & 21 & 0.0002 \\
Extended Data Fig. 1-1D & 2.432 & 15 & 0.0280 \\
Extended Data Fig. 1-1E & 0.704 & 5 & 0.5129 \\
Extended Data Fig. 1-1F & 0.022 & 7 & 0.9829 \\
Extended Data Fig. 1-1I & 2.776 & 17 & 0.0130 \\
Extended Data Fig. 1-1J & 3.392 & 17 & 0.0035 \\
Extended Data Fig. 2-1A & 688.100 & 2 & $<0.0001$ \\
Extended Data Fig. 2-1B & 1319.000 & 2 & $<0.0001$ \\
Extended Data Fig. 2-1C & 598.900 & 2 & $<0.0001$ \\
Extended Data Fig. 2-1D & 220.900 & 2 & $<0.0001$ \\
Extended Data Fig. 3-1D & 3.935 & 30 & 0.0005 \\
Extended Data Fig. 4-1, cerebrum & 0.191 & 4 & 0.8580 \\
Extended Data Fig. 4-1, thalamus & 0.691 & 4 & 0.5274 \\
Extended Data Fig. 4-1, striatum & 0.084 & 4 & 0.9372
\end{tabular}

For the Student's $t$ tests used in our analyses, the $t$ values, df, and $p$ values are summarized. 
Table 4: Information for one-way ANOVA

\begin{tabular}{|c|c|c|c|c|c|}
\hline & SS & $\mathrm{df}$ & MS & $F_{(\mathrm{dfn}, \mathrm{dfd})}$ & $p$ \\
\hline \multicolumn{6}{|l|}{$\overline{\text { Fig. 1C }}$} \\
\hline Between columns & 43308629 & 2 & 21654315 & \multirow{3}{*}{$F_{(2,31)}=4.748$} & \multirow[t]{3}{*}{$p=0.0159$} \\
\hline Within columns & 141389895 & 31 & 4560964 & & \\
\hline Total & 184698524 & 33 & & & \\
\hline \multicolumn{6}{|l|}{ Fig. $1 D$} \\
\hline Between columns & 17029 & 2 & 8514 & \multirow{3}{*}{$F_{(2,31)}=6.306$} & \multirow[t]{3}{*}{$p=0.0050$} \\
\hline Within columns & 41856 & 31 & 1350 & & \\
\hline Total & 58885 & 33 & & & \\
\hline \multicolumn{6}{|l|}{ Fig. $2 B$} \\
\hline Between columns & 18214401 & 2 & 9107200 & \multirow[t]{3}{*}{$F_{(2,22)}=3.247$} & \multirow[t]{3}{*}{$p=0.0581$} \\
\hline Within columns & 61708704 & 22 & 2804941 & & \\
\hline Total & 79923105 & 24 & & & \\
\hline \multicolumn{6}{|l|}{ Fig. $2 C$} \\
\hline Between columns & 21480 & 2 & 10740 & \multirow{3}{*}{$F_{(2,26)}=15.97$} & \multirow[t]{3}{*}{$p<0.0001$} \\
\hline Within columns & 17489 & 26 & 672.7 & & \\
\hline Total & 38969 & 28 & & & \\
\hline \multicolumn{6}{|l|}{ Fig. $5 B$} \\
\hline Between columns & 2577676 & 2 & 1288838 & \multirow[t]{3}{*}{$F_{(2,26)}=3.614$} & \multirow[t]{3}{*}{$p=0.0412$} \\
\hline Within columns & 9272962 & 26 & 356652 & & \\
\hline Total & 11850639 & 28 & & & \\
\hline \multicolumn{6}{|l|}{ Fig. $5 C$} \\
\hline Between columns & 14905 & 2 & 7453 & \multirow[t]{3}{*}{$F_{(2,26)}=3.92$} & \multirow[t]{3}{*}{$p=0.0325$} \\
\hline Within columns & 49424 & 26 & 1901 & & \\
\hline Total & 64329 & 28 & & & \\
\hline \multicolumn{6}{|c|}{ Extended Data Fig. 1-1G } \\
\hline Between columns & 473 & 2 & 236.5 & \multirow{3}{*}{$F_{(2,31)}=6.304$} & $p=0.0050$ \\
\hline Within columns & 1163 & 31 & 37.51 & & \\
\hline Total & 1636 & 33 & & & \\
\hline Extended Data Fig. 1 & & & & & \\
\hline Between columns & 136.1 & 2 & 68.07 & $F_{(2,31)}=2.005$ & $p=0.1518$ \\
\hline Within columns & 1053 & 31 & 33.96 & & \\
\hline Total & 1189 & 33 & & & \\
\hline Extended Data Fig. 2 & & & & & \\
\hline Between columns & 11.75 & 2 & 5.876 & $F_{(2,8)}=16.19$ & $p=0.0015$ \\
\hline Within columns & 2.904 & 8 & 0.363 & & \\
\hline Total & 14.66 & 10 & & & \\
\hline Extended Data Fig. 2 & & & & & \\
\hline Between columns & 597.6 & 2 & 298.8 & $F_{(2,26)}=15.92$ & $p<0.0001$ \\
\hline Within columns & 488 & 26 & 18.77 & & \\
\hline Total & 1086 & 28 & & & \\
\hline Extended Data Fig. 2 & & & & & \\
\hline Between columns & 230.5 & 2 & 115.3 & $F_{(2,26)}=3.902$ & $p=0.0330$ \\
\hline Within columns & 768 & 26 & 29.54 & & \\
\hline Total & 998.5 & 28 & & & \\
\hline Extended Data Fig. 5 & & & & & \\
\hline Between columns & 414 & 2 & 207 & $F_{(2,26)}=3.921$ & $p=0.0325$ \\
\hline Within columns & 1373 & 26 & 52.8 & & \\
\hline Total & 1787 & 28 & & & \\
\hline Extended Data Fig. 5 & & & & & \\
\hline Between columns & 78.67 & 2 & 39.34 & $F_{(2,26)}=1.724$ & $p=0.1981$ \\
\hline Within columns & 593.2 & 26 & 22.82 & & \\
\hline Total & 671.9 & 28 & & & \\
\hline
\end{tabular}

For our one-way ANOVA analyses, the SS, df, the MS, F ratios, and $p$ values used to assess the variation between columns, within columns, and total are summarized.

\section{Results}

Mice deficient for genes regulating the inflammasome Cascade exhibit behavior abnormalities

Since a previous report showed that $I I-1 r^{-/-}$mice exhibit aberrant behaviors, such as hyperactivity and low anxiety (Murray et al., 2013), we decided to use a panel of behavior assays to assess the global impact of inflammasomes on mouse brain development (Table 1). We first investigated the role of CASP1 in mouse brain because it is a common downstream target of inflammasomes and because multiple inflammasome complexes are expressed in microglia and macrophages (Walsh et al., 2014). We found that male Casp $1^{-1-}$ mice showed hyperactivity 
(Fig. $1 A$ ) and low anxiety levels (Fig. 1B; Extended Data Fig. 1-1B,C), as determined by the open field and elevated plus maze assays, respectively, that were similar to the behavior abnormalities observed in $I-1 r^{-1-}$ mice. We also noticed that male Casp $1^{-1-}$ mice showed less attention to light stimuli compared with WT mice, as measured by the 5-CSRTT (Extended Data Fig. 1-1D; Sanchez-Roige et al., 2012). However, we did not observe other behavioral abnormalities, including decreased sociability, defective learning and memory, or increased restricted repetitive behavior (data not shown). Interestingly, these behavior changes were only observed in male, but not female, Casp $1^{-1-}$ mice [Fig. 1A,B (male); Extended Data Fig. $1-1 E, F$ (female)], which is consistent with several reports suggesting that some neurodevelopmental disorders show sex dimorphisms (Rucklidge, 2010).

Since both GSDMD and pro-IL-1 $\beta$ are cleaved by CASP1 (Extended Data Fig. 1-1A) as part of the inflammasome pathway, we also used Gsdmd-deficient and II-1rdeficient mice (Kayagaki et al., 2015; Shi et al., 2015) in our behavior studies. Our results showed that Gsdmd ${ }^{-1-}$ mice exhibited hyperactivity (Fig. $1 C$ ) and low anxiety (Fig. 1D; Extended Data Fig. 1-1G,H). Furthermore, consistent with the previous report, we observed behavior abnormalities in $I I-1 r^{-1-}$ mice, although to a lesser extent (Fig. 1C, $D$; Extended Data Fig. 1-1G,H). Next, we hypothesized that NLRP3 might be the inflammasome protein responsible for the activation of CASP1 in the fetal brain because NLRP3 detects tissue damage rather than infection (Cassel and Sutterwala, 2010) and because the developing brain in the uterus should be a sterile environment. In addition, NLRP3 could be activated by ATP and ions released from dying/dead cells, given the widespread death of newly differentiated neurons during fetal brain development (Watson et al., 2012). To test this hypothesis, we ran our behavior assays on NIrp3 ${ }^{-1-}$ mice and found that they also exhibited hyperactivity (Fig. $1 E$ ) and low anxiety (Fig. $1 F$; Extended Data Fig. 1-1/,J). From these results, we concluded that the NLRP3-CASP1-GSDMD/IL-1 $\beta$ pathway is required for establishing normal behavior in mice.

\section{Re-expression of Casp1 in CX3CR1 ${ }^{+}$cells restores normal behaviors}

The expression of chemokine receptor CX3CR1 is characteristic for myeloid-lineage cells, including microglial cells. In the brain, $\mathrm{CX} 3 \mathrm{CR} 1^{+}$cells in the parenchyma are considered microglial cells; however, there are some neutrophils and subsets of macrophages in the meninges and blood vessels that also express CX3CR1 (Mizutani et al., 2012; Wolf et al., 2013). Our gene expression studies showed that Casp1 and NIrp3 mRNAs were highly expressed in $\mathrm{CX} 3 \mathrm{CR} 1^{+}$cells, including microglia and macrophages, isolated from fetal brain (Extended Data Fig. 2$1 A, B)$. In contrast, $\mathrm{CX} 3 \mathrm{CR} 1^{-}$cells displayed high expression levels of Cd200 and Celf4 mRNAs, which are associated with neural cells (Extended Data Fig. 2-1C,D; Haimon et al., 2018). Because the Casp $1^{-1-}$ mice used in our initial studies were conventional knock-out mice in which Casp1 was deleted from all cell types, Casp $1^{-1-}$ mice expressing a Cre-inducible Casp1 allele (Rosa26-
LoxP-STOP-LoxP-Casp1-IRES-GFP, iCasp1 mice; Rauch et al., 2017) were crossed to BAC transgenic mice expressing Cre under the control of the $\mathrm{C} \times 3 \mathrm{cr} 1$ promoter, a commonly used Cre-driver enriched in microglia (Wolf et al., 2013), so that Casp1 would be re-expressed in CX $3 \mathrm{CR} 1^{+}$cells. The resulting Casp $1^{-1-}$; iCasp1; Cx3cr1Cre (experimental) mice and their Casp $1^{-1-}$; iCasp1 littermate controls (control, equivalent to Casp $1^{-\prime-}$; Fig. $2 A$ ) as well as WT mice were then used in our previously described behavior assays (Table 1) to verify that re-expression of Casp1 in immune cells is necessary for preventing behavior abnormalities and ensuring normal brain development. Remarkably, re-expression of Casp 1 in $\mathrm{CX} 3 \mathrm{CR} 1^{+}$cells (Extended Data Fig. 2-1E) resulted in animals without hyperactivity (Fig. $2 B$ ) or low anxiety levels (Fig. 2C; Extended Data Fig. 2-1F,G); thus, we concluded that Casp1 expression in $\mathrm{CX} 3 \mathrm{CR} 1^{+}$myeloid cells, including microglial cells, plays an essential role in establishing normal behaviors.

\section{Lytic cell death occurs in a spatiotemporal manner in the mouse fetal brain}

Lytic cell death, downstream of the inflammasome pathway, has been described in macrophages and dendritic cells as well as in aged microglia in the context of Alzheimer's disease (Heneka et al., 2013). However, it is not known whether microglia undergo lytic cell death during fetal brain development. Because mice deficient for Gsdmd, a factor that is essential for the induction of lytic cell death (Shi et al., 2015), exhibited behavior abnormalities similar to those observed in Casp1-deficient mice (Fig. $1 A-D$ ), we hypothesized that fetal microglia might undergo lytic cell death. To investigate whether microglial cell death occurs during early brain development, PI (a DNA dye) was used to visualize dying microglia. PI is able to stain these cells because during lytic cell death, plasma membrane integrity is lost, allowing the dye into the cells (Fink and Cookson, 2005; Zhang et al., 2018). For this assay, PI was injected into pregnant WT females that had been crossed with $\mathrm{C} \times 3 \mathrm{cr} 1^{\text {GFP/GFP }}$ male mice at specific days during fetal brain development. The genotype of the resulting offspring was $C \times 3 c r 1^{G F P /+}$, with microglia that were labeled with GFP (Jung et al., 2000). While it is known that $\mathrm{C} \times 3 \mathrm{cr} 1$ is expressed in non-microglial cells outside the brain, Cx3cr1-GFP ${ }^{+}$cells in the brain parenchyma are considered microglia (Mizutani et al., 2012). Following PI injection, embryos were recovered, the tissue was cleared using the CUBIC method (Susaki et al., 2014), and the brains were imaged via LSFM (Fig. $3 A$ ). Interestingly, our imaging revealed discrete clusters of $\mathrm{GFP}^{+} \mathrm{PI}^{+}$cells in both the lateral ganglionic eminence (LGE), which matures into a major part of the striatum, and the intermediate thalamus (iTh) starting at E12.5 (Fig. $3 B$; Extended Data Fig. 3-1A). These clusters were also noted in both the LGE and iTh at E14.5 (Fig. 3C,E; Extended Data Fig. 3-1B; Movie 1), coincident with active neurogenesis and neuronal cell death (Watson et al., 2012). Clusters were comprised of 20-200 microglial cells, with averages of 107 and 85 cells/cluster in the LGE and iTh, respectively, at E14.5 (Extended Data Fig. 3-1B) 
A

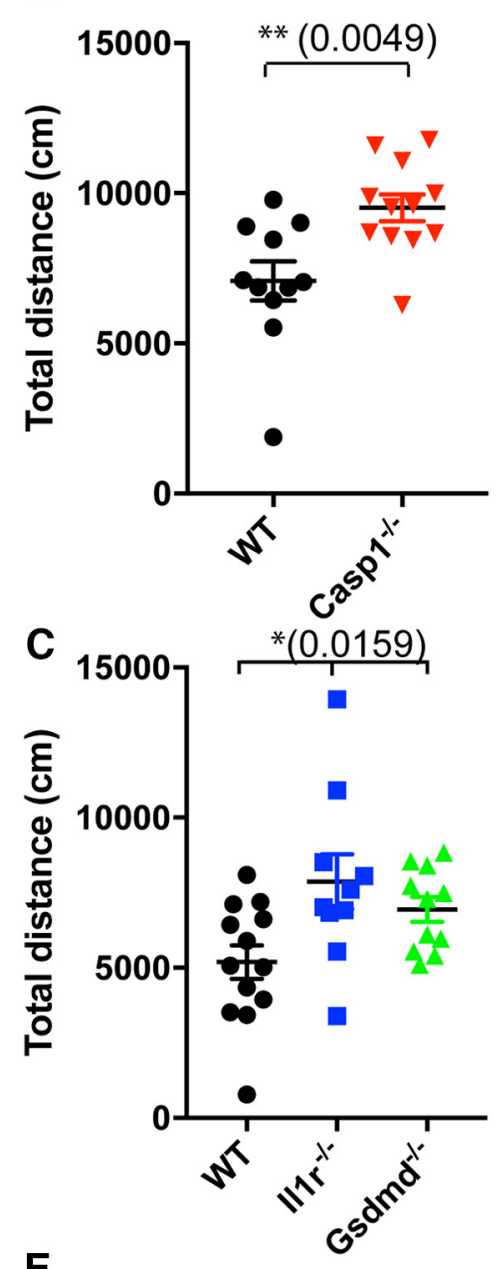

E

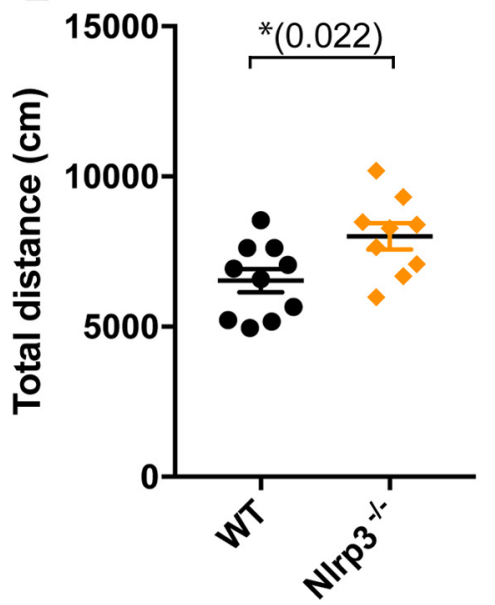

B
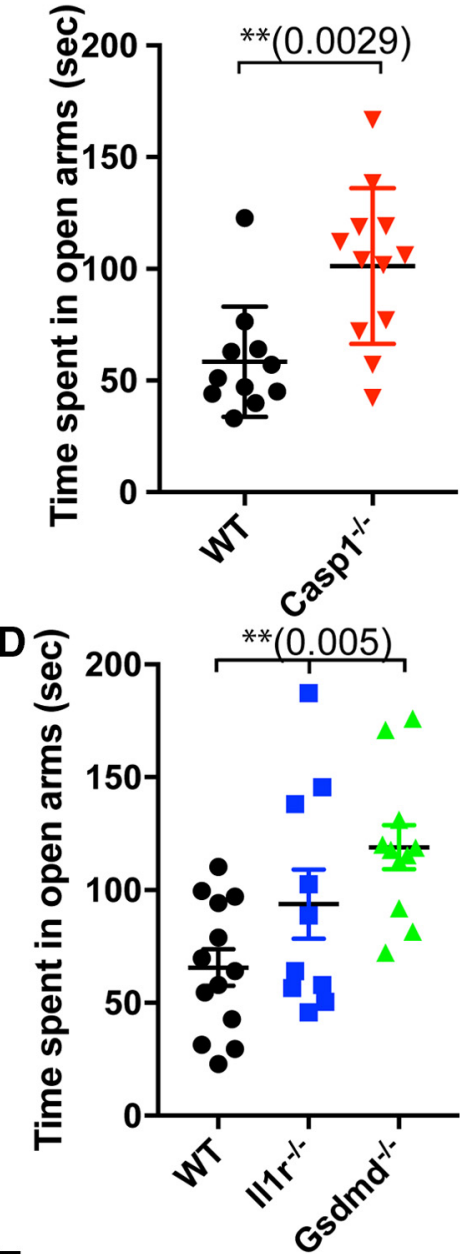

$\mathbf{F}$

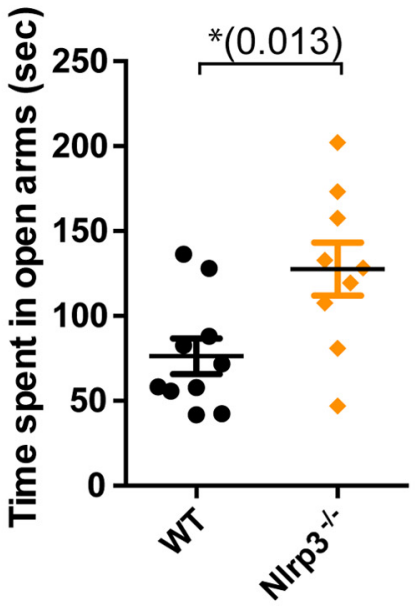

Figure 1. Mice deficient for inflammasome pathway genes exhibit behavior abnormalities. This figure is supported by Extended Data Figure 1-1. A, General activity of male WT (black circles, $N=11$, from 5 litters) and Casp $1^{-1-}$ (red triangles, $N=12$, from 5 litters) mice was determined by open field assay and is shown as total distance moved (centimeters); $p=0.0049$, $\mathrm{df}=21, t=3.142$. $\boldsymbol{B}$, Anxiety levels of male WT and Casp $1^{-1}$ mice were determined using the elevated plus maze assay and are shown as time spent in open arms (seconds); $p=0.0029, \mathrm{df}=21, t=3.371$. $\boldsymbol{C}, \boldsymbol{D}$, General movement $(\boldsymbol{C})$ and anxiety levels $(\boldsymbol{D})$ of male WT (black circles,

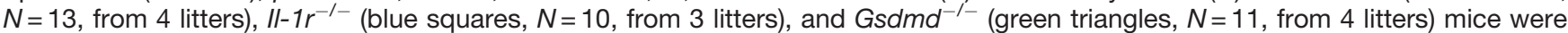
determined as in $\boldsymbol{A}, \boldsymbol{B}$, respectively. $\boldsymbol{C}, p=0.0159, \mathrm{df}=33, F=4.748$. Tukey's multiple comparison test: WT versus $11-1 r^{-1-}$ $p=0.0147$, WT versus Gsdmd ${ }^{-1-} p=0.1270, I l-1 r^{-1-}$ versus $\mathrm{Gsdm}^{-/-} p=0.5866 . \boldsymbol{D}, p=0.0050, \mathrm{df}=33, F=6.306$. Tukey's multiple

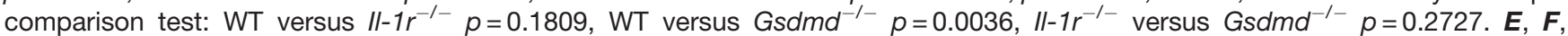
General movement $(\boldsymbol{E})$ and anxiety $(\boldsymbol{F})$ of male WT (black circles, $N=10$, from 3 litters) and NIrp3-/- mice (orange diamonds, $N=9$, 
continued

from 2 litters) were determined as in $\boldsymbol{A}, \boldsymbol{B}$, respectively. $\boldsymbol{E}, p=0.0220, \mathrm{df}=17, t=2.520 . \boldsymbol{F}, p=0.0130, \mathrm{df}=17, t=2.776$. Data shown are individual mice and error bars indicate standard error of the mean (SEM); ${ }^{*} p<0.05,{ }^{* *} p<0.01$.

and fewer cells at E12.5 (data not shown). To determine whether the cells in the clusters experienced lytic cell death, we measured the diameters of $\mathrm{GFP}^{+}$and $\mathrm{GFP}^{+} \mathrm{PI}^{+}$ cells and found that $\mathrm{GFP}^{+} \mathrm{PI}^{+}$cells had significantly larger diameters, suggesting that these cells had lost membrane integrity and were swollen (Extended Data Fig. 3-1C,D).

Since CASP1 activation is required for lytic cell death (Extended Data Fig. 1-1A), we next tested whether the

A

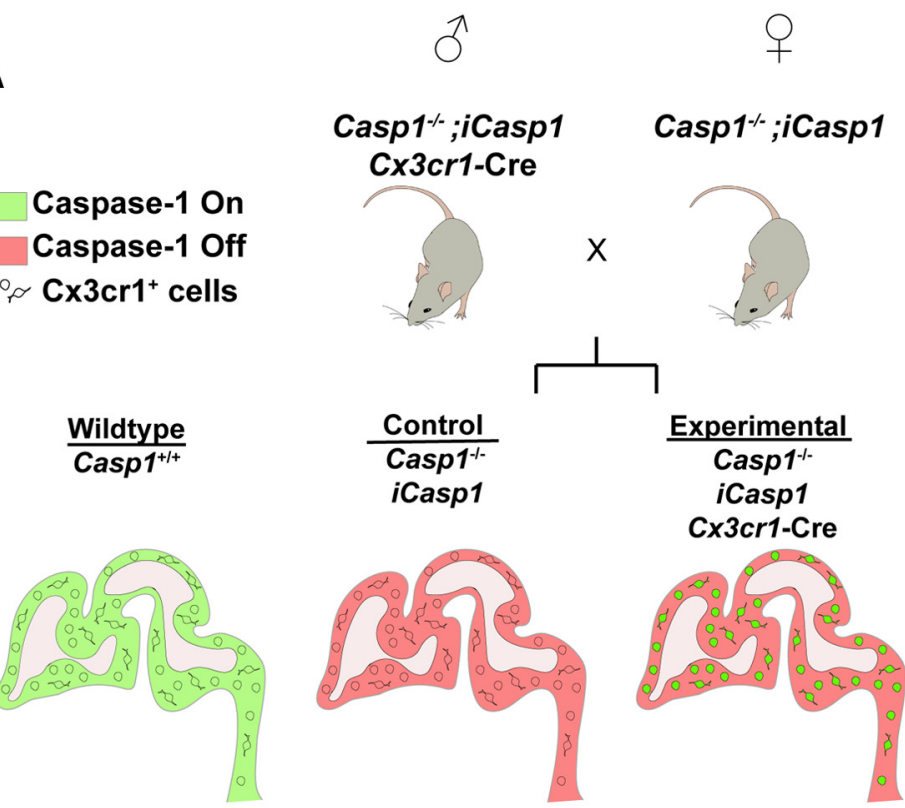

B

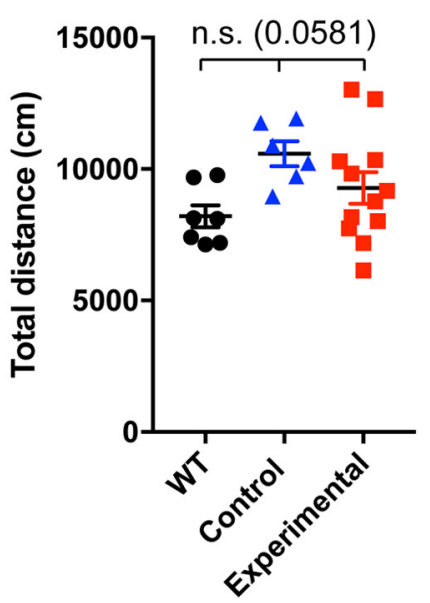

C

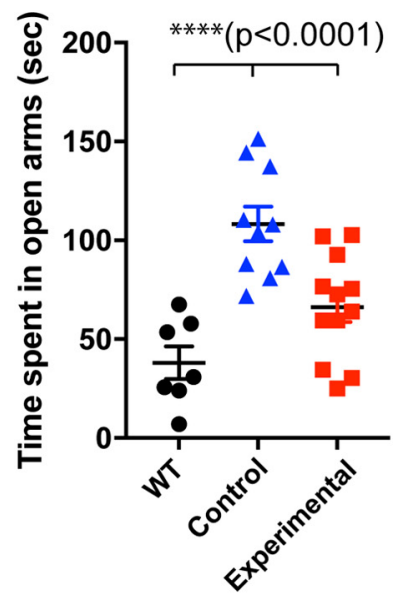

Figure 2. Casp1 re-expression in $\mathrm{CX} 3 \mathrm{CR} 1^{+}$cells restores normal behavior. This figure is supported by Extended Data Figure 2-1. $\boldsymbol{A}$, Experimental design is shown. Three mouse lines $\left(\right.$ Casp $1^{-1-}$, iCasp1, and Cx3cr1-Cre) were crossed to generate Casp $1^{-1-}$; iCasp1; Cx3cr1-Cre positive mice (experimental) and Casp 1 ${ }^{-1-}$; iCasp1; Cre negative littermates (control). Mice expressing Cre had induced expression of Casp1 in $\mathrm{CX} 3 \mathrm{CR} 1^{+}$cells, but not in CX3CR1 ${ }^{-}$cells. B, General movement of male WT (black circles, $N=7$, from 3 litters), littermate control (blue triangles, $N=6$, from 4 litters), and experimental (red squares, $N=12$, from 8 litters) mice was determined by open field assay and is shown as total distance moved (centimeters); $p=0.0581, \mathrm{df}=24, F=3.247$. Tukey's multiple comparison test: WT versus control $p=0.0997$, WT versus experimental $p=0.5502$, control versus experimental $p=0.3072$. $\boldsymbol{C}$, Anxiety levels of male WT (black circles, $N=7$, from 3 litters), control (blue triangles, $N=10$, from 6 litters), and experimental (red squares, $N=12$, from 8 litters) mice were determined by elevated plus maze assay and are shown as time spent in open arms (seconds); $p<0.0001, \mathrm{df}=28, F=15.97$. Tukey's multiple comparison test: WT versus control $p<0.0001$, WT versus experimental $p=0.0760$, control versus experimental $p=0.0023$. Data indicates individual animals and error bars are shown as SEM; ${ }^{\star \star \star \star} p<0.0001$; n.s., not significant. 


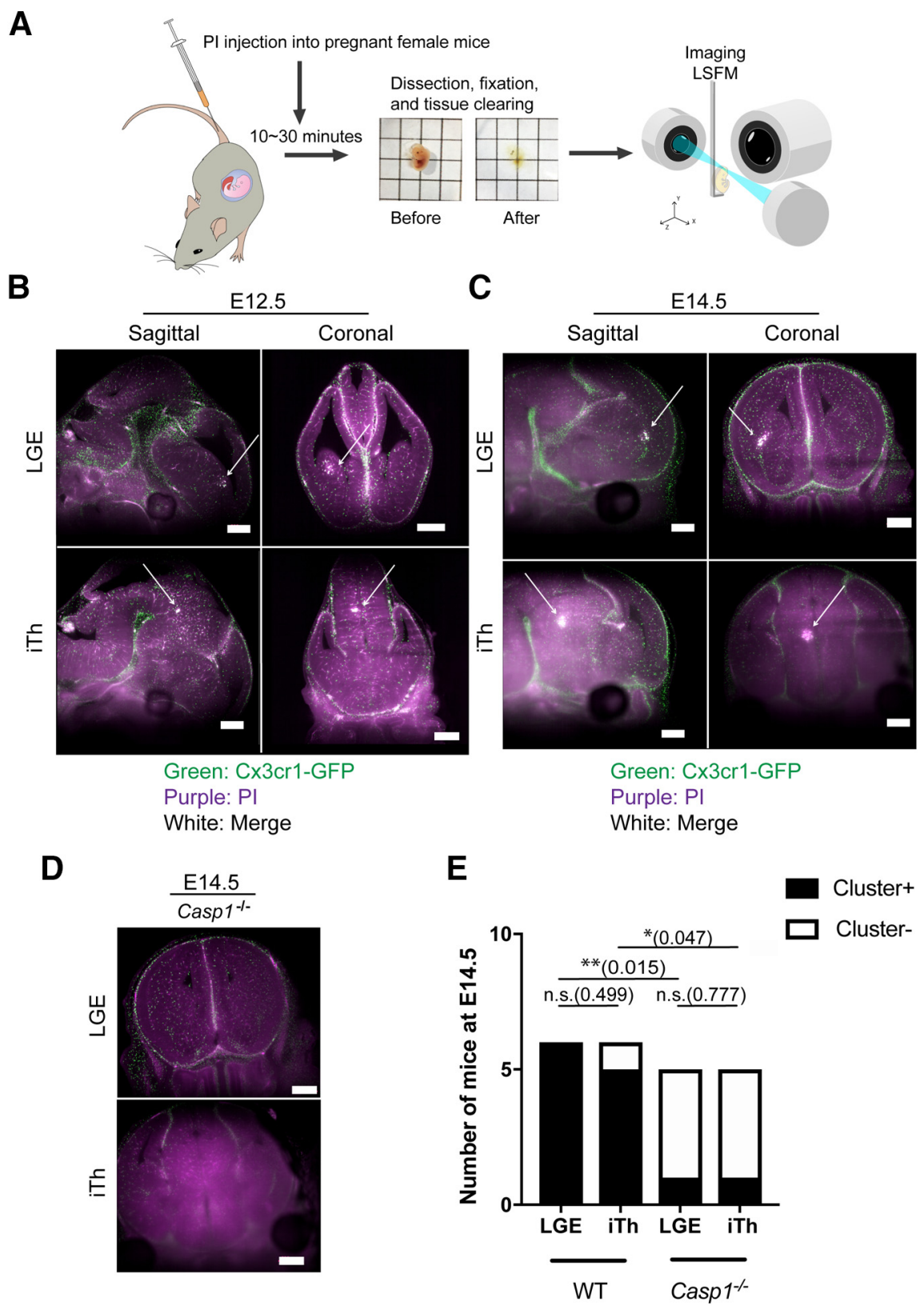

Figure 3. Lytic cell death occurs in a spatiotemporal manner in the fetal brain. This figure is supported by Extended Data Figure 3-1 and Movies 1, 2. A, Experimental scheme is shown. PI was injected into pregnant female mice at specific gestational stages. Ten to 30 min after PI injection, total fetal bodies were recovered, cleared, and imaged by LSFM. B, Representative sagittal and coronal LSFM images of the LGE and primitive iTh of a WT E12.5 fetal brain (male, $N=6$, from 2 litters) are shown. Arrows indicate the cluster. Green, GFP; purple, PI. Scale bars: $500 \mu \mathrm{m}$. C, Representative images of a WT E14.5 fetal brain (male, $N=6$, from 3 litters) are shown. Arrows indicate the cluster. Green, GFP; purple, PI. Scale bars: $500 \mu \mathrm{m}$. $\boldsymbol{D}$, Representative coronal LSFM images of a Casp $1^{-1-}$ brain (male, $N=5$, from 3 litters) at E14.5 are shown. Scale bars: $500 \mu \mathrm{m}$. $\boldsymbol{E}$, Numbers of mice that exhibited clusters in the LGE and iTh at E14.5 are shown; ${ }^{*} p<0.05,{ }^{* \star} p<0.01 ;$ n.s., not significant.

observed cell death was impaired in Casp $1^{-1-}$ mice. Using Cx3cr1 $1^{\text {GFP/GFP }}$ mice crossed with $\mathrm{Casp}^{-1-}$ mice, we found that the formation of $\mathrm{GFP}^{+} \mathrm{PI}^{+}$cell clusters in the LGE and iTh was significantly reduced in Casp $1^{-1-}$; Cx3cr1-GFP offspring at E14.5 (Fig. 3D,E; Movie 2). Conversely, in Casp1 1--; iCasp1; Cx3cr1-Cre (experimental) mice, which express GFP following Cre-mediated recombination (Rauch et al., 2017; Fig. 2A), we observed GFP $^{+}$cells that were also positive for PI signal (Extended
Data Fig. 3-1E). Overall, these results suggest that microglia in the LGE and iTh undergo lytic cell death during fetal brain development at E12.5-E14.5 in a Casp1-dependent manner.

\section{The thalamic reticular nucleus (TRN) region in Casp $1^{-1-}$ brains has increased numbers of neurons}

In mice, neural progenitor cells (NPCs) start to differentiate at E12.5, coincident with the microglial lytic cell 


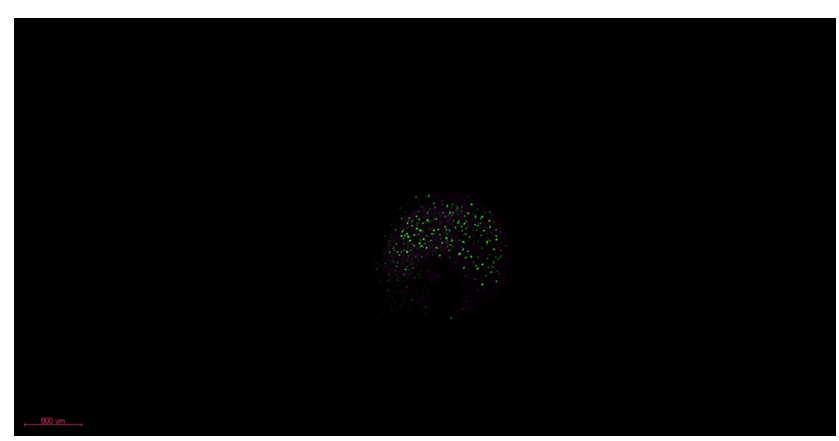

Movie 1. Representative LSFM imaging of male E14.5 WT fetal brain. Embryos had one copy of $C \times 3 c r 1-G F P$ and were injected with PI 10-30 min before tissue harvest and visualization. Movies show sequential z-planes of a typical acquisition followed by 3D maximum intensity projection. Purple, PI; green, Cx3cr1-GFP; white, merged. [View online]

death that we observed in the fetal brain. Therefore, we hypothesized that defective microglial cell death might influence NPCs in the developing brain. To determine whether there were NPCs in the $\mathrm{GFP}^{+} \mathrm{PI}^{+}$clusters, we performed our LSFM analysis on Cx3cr1 ${ }^{\text {GFP/+ }}$ mice, with the addition of anti-Pax6 antibody to stain Pax $6^{+}$NPCs in the brain. Our imaging showed that the $\mathrm{GFP}^{+} \mathrm{PI}^{+}$clusters were indeed associated with NPCs in the fetal brain (Fig. $4 A$ ). Based on this result, we hypothesized that defective lytic cell death of microglia might contribute to alterations in brain structures resulting from improper development of NPCs and neurons derived from the LGE and iTh. To test our hypothesis, we measured the volumes of major parts of the cerebrum as well as descendants of the LGE (striatum) and iTh (thalamus) and found that there were no

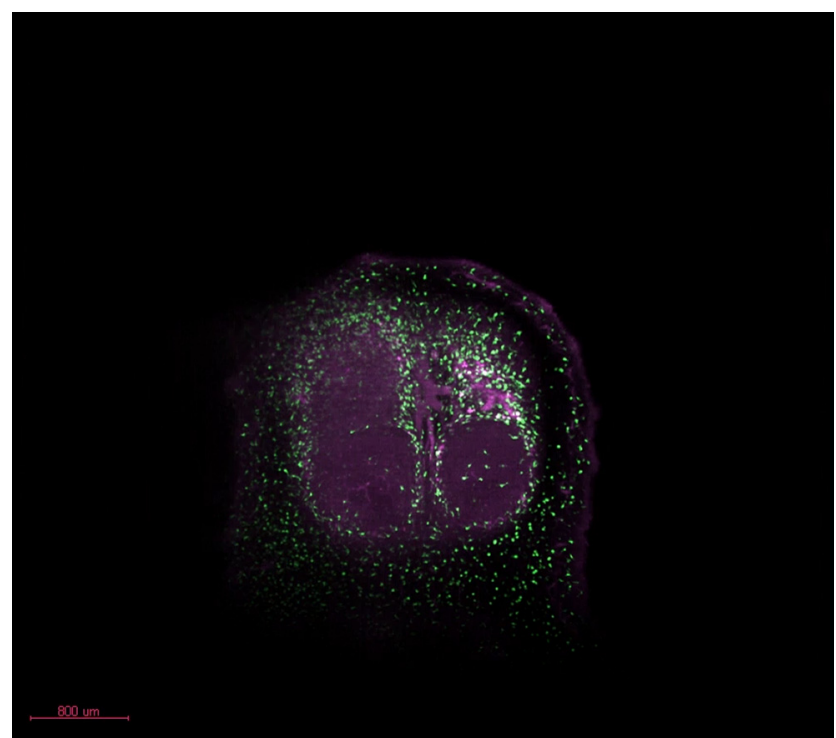

Movie 2. Representative LSFM imaging of male E14.5 Casp $1^{-1-}$ fetal brain. Embryos had one copy of Cx3cr1-GFP and were injected with PI 10-30 min before tissue harvest and visualization. Movies show sequential z-planes of a typical acquisition followed by 3D maximum intensity projection. Purple, PI; green, Cx3cr1-GFP; white, merged. [View online] differences between adult WT and Casp $1^{-1-}$ mice (Extended Data Fig. 4-1) in these areas.

Because we did not observe gross structural anomalies in the thalamus, or striatum, we next tested whether we could observe finer compositional changes. Since previous reports have suggested that $\mathrm{IL}-1 \beta$ plays important roles in NPC death, proliferation, and differentiation (Crampton et al., 2012; Guadagno et al., 2015), and because the timing of these events are before circuit establishment, we hypothesized that defective microglial lytic cell death may change the numbers of cells located within structures descending from the LGE and iTh. Therefore, we serially sectioned entire cerebrums of adult WT and Casp $1^{-1-}$ mice and then immunostained them with antiNeuN antibody to identify neurons. While we did not find obvious cellular changes in regions descending from the LGE, we found increased numbers of neurons in the TRN (parvalbumin ${ }^{+}$cells) a region developed from the iTh, in Casp $1^{-1-}$ mice (Fig. 4B,C). These results suggest that appropriate microglial lytic cell death may be important for regulating proper neuronal numbers in certain brain compartments.

\section{Increased microglial numbers are not observed in the TRN of adult Casp1 ${ }^{-/-}$mice}

Since the death of fetal microglia in Casp $1^{-1-}$ mice was impaired, and microgliosis (increased numbers of microglia) is often associated with pathologic conditions in the brain (Lull and Block, 2010; Brück et al., 2016), we hypothesized that the number of microglia in the TRN might be increased, resulting in disrupted neuronal homeostasis. To test this hypothesis, we measured the number of microglia using anti-lba1 antibody staining in the TRN. Our results showed that despite the lack of lytic cell death in $\mathrm{Casp}^{-1-}$ mice, microglial numbers in the TRN were not increased (Fig. 4D,E), suggesting that the behavior abnormalities observed in these mice are not because of microgliosis in the brain.

\section{Injecting inflammasome pathway inhibitors into dams results in behavioral abnormalities in offspring}

Since we observed that lytic cell death occurred on specific days during fetal brain development and microglial death might be necessary for the proper differentiation of NPCs, we hypothesized that inhibition of the NLRP3-CASP1-GSDMD/IL-1 $\beta$ pathway during this developmental window might be sufficient to induce behavior abnormalities similar to those observed in Casp1 $1^{-1-}$ mice. To test this hypothesis, WT pregnant mothers were injected with specific drug inhibitors of CASP1 and NLRP3 (VX-765 and MCC950, respectively; Coll et al., 2015) at E12.5, E13.5, and E14.5, times when we observed lytic cell death in WT fetal brains, and then behavior assays were performed on the offspring to determine their activity and anxiety levels (Fig. 5A). Our results showed that male offspring from MCC950-injected mice (and, to a lesser extent, VX-765-injected mice) showed hyperactivity (Fig. $5 B$ ) and low anxiety levels (Fig. 5C; Extended Data Fig. 5-1A,B). These 


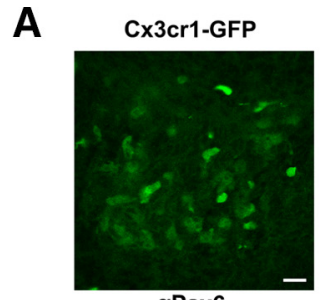

aPax6

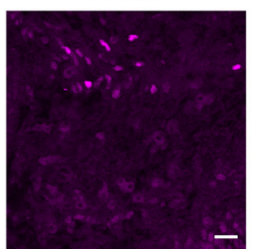

B

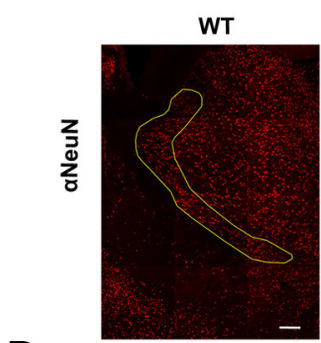

D

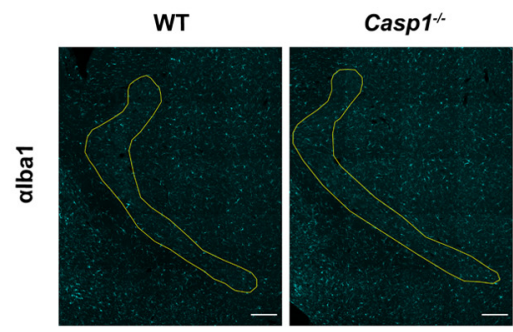

PI

Merge

Casp1\%

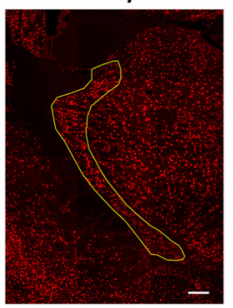

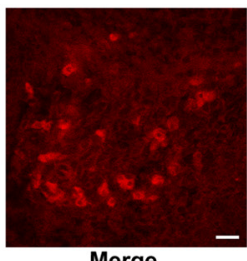

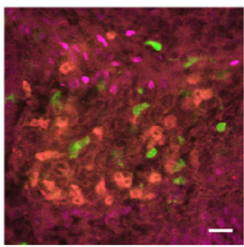

$\mathbf{E}$

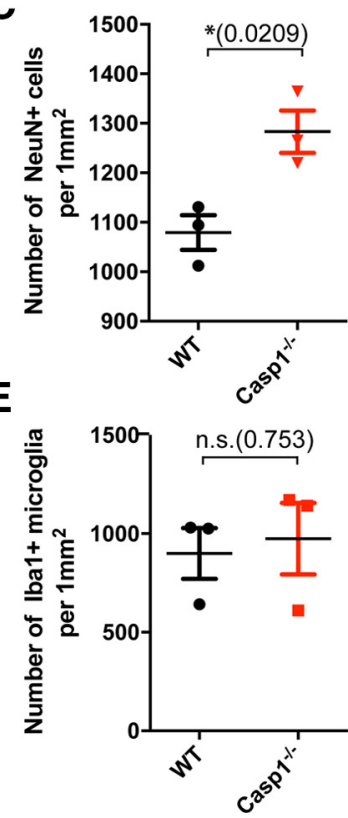

Figure 4. Numbers of neurons but not microglia are increased in the TRN in adult Casp $1^{-1-}$ mice. This figure is supported by Extended Data Figure 4-1. A, Enlarged image of the $\mathrm{GFP}^{+} \mathrm{PI}^{+}$cluster shown in Figure 3. Mice were injected with $\mathrm{PI}$ as shown in Figure $3 A$, and fetal brain slices were stained with anti-Pax6 antibody. Images of $C \times 3 c r 1$-GFP (top left), PI (top right), anti-Pax6 (bottom left), and merged signals are shown. Scale bar: $50 \mu \mathrm{m}$. B, Representative images of anti-NeuN staining signals from male $\operatorname{Casp}^{-l-}(N=3$, right, from 2 litters) and sex/age-matched WT $(N=3$, left, from 2 litters) adult brains are shown. TRN regions are outlined in yellow. Scale bar: $200 \mu \mathrm{m}$. C , Average anti-NeuN signals from Casp $1^{-1-}$ (red triangles) and WT (black circles) mice are shown as cell number $/ \mathrm{mm}^{2}$. Dots indicate individual animals and are the average cell numbers from a total of six serial sections stained as shown in $\boldsymbol{B} ; \boldsymbol{p}=0.0209, \mathrm{df}=4, t=3.694$. Error bars indicate SEM; ${ }^{\star} p<0.05$. $\boldsymbol{D}$, Representative images of anti-lba1 antibody staining in the TRNs (regions outlined in yellow) of male WT ( $N=3$, left, from 2 litters) and Casp $1^{-1-}(N=3$, right, 2 litters) mice are shown. Scale bar: $200 \mu \mathrm{m}$. E, Average number of Iba1 ${ }^{+}$cells in Casp $1^{-1-}$ (red triangles) and WT (black circles) mice are shown as mean cell number $/ \mathrm{mm}^{2}$. Dots indicate individual animals and are the average of cell numbers from a total of six serial sections stained as shown in $\boldsymbol{D} ; p=0.7533, \mathrm{df}=4, t=0.336$. Error bars indicate SEM; n.s., not significant.

results suggest that pharmacological disruption of the NLRP3/CASP1 pathway, especially NLRP3 inhibition (MCC950), during development may be sufficient to induce the behavior abnormalities observed in our knockout mice. Our working model is that the NLRP3-CASP1GSDMD/IL- $1 \beta$ cascade in microglia is essential for normal brain development, and that genetic or pharmacological disruption of this pathway leads to aberrant behavior in mice (Fig. 5D). We also propose that disruption of this pathway may impact the development of NPCs, thus resulting in increased numbers of neurons in the TRN, a region descendant from the iTh, which may cause atypical behaviors in mice.

\section{Discussion}

In this study, we have shown that the NLRP3-CASP1GSDMD/IL-1 $\beta$ cascade in microglia is required for normal brain development and prevents behavior abnormalities such as hyperactivity and low anxiety levels (Fig. 1). Casp1 and N/rp3 are predominantly expressed in CX3CR $1^{+}$myeloid-lineage cells in the fetal brain, and our data showed that 
A

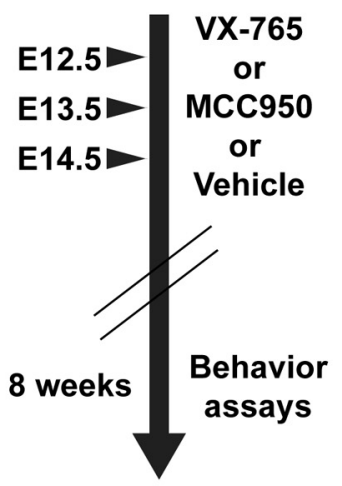

C

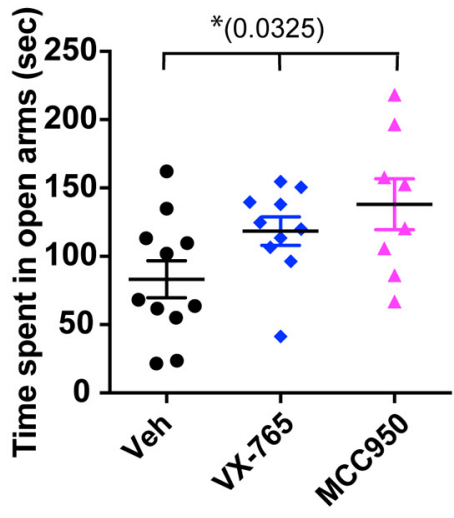

B

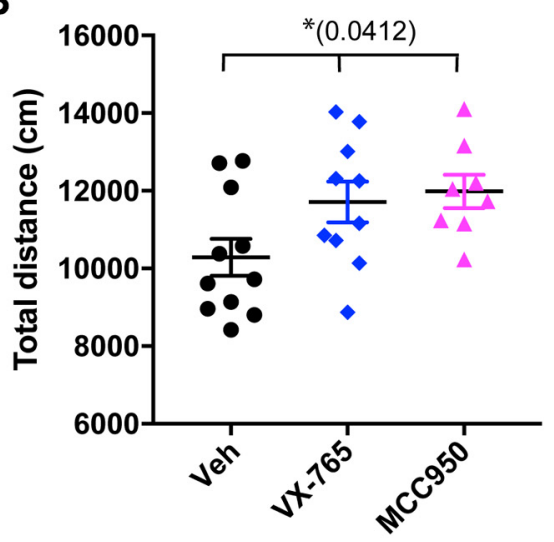

D

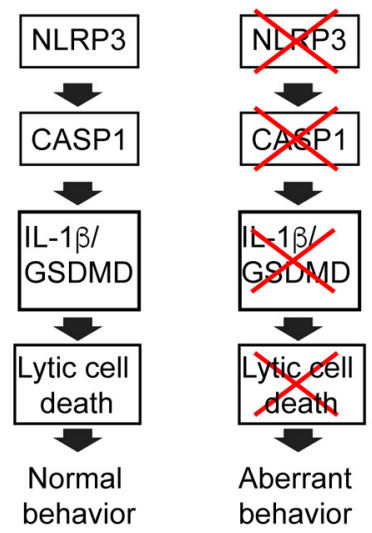

Figure 5. Fetal exposure to inflammasome inhibitors leads to aberrant behaviors. This figure is supported by Extended Data Figure 5-1. A, Experimental scheme is shown. Pregnant WT female mice were injected with inflammasome inhibitors (VX-765 or MCC950 to inhibit CASP1 or NLRP3, respectively) or control (Veh: vehicle) at E12.5, E13.5, and E14.5. Behaviors of the male offspring of injected mice were tested at eight weeks old. $\boldsymbol{B}$, General activity of the male offspring of control-injected (vehicle; black circles, $N=11$, from 3 litters), VX-765-injected (blue diamonds, $N=10$, from 3 litters), and MCC950-injected mothers (pink triangles, $N=8$, from 3 litters) was determined by open field assay and is shown as the total distance moved (centimeters); $p=0.0412, \mathrm{df}=28$, $F=3.614$. Tukey's multiple comparison test: Veh versus VX-765 $p=0.0963$, Veh versus MCC950 $p=0.0591$, VX-765 versus MCC950 $p=0.9250$. Dots indicate individual animals, and error bars indicate SEM. $\boldsymbol{C}$, Anxiety levels in the indicated offspring were determined by elevated plus maze assay and are shown as time spent in open arms (seconds); $p=0.0325, \mathrm{df}=28, F=3.92$. Tukey's multiple comparison test: Veh versus VX-765 $p=0.1736$, Veh versus MCC950 $p=0.0307$, VX-765 versus MCC950 $p=0.6151$. Data are shown as individual animals, and error bars indicate SEM; ${ }^{*} p<0.05$; n.s., not significant. $\boldsymbol{D}$, Working model is shown. Activation of the NLRP3-CASP1-GSDMD/IL-1 $\beta$ cascade in fetal microglia is required for normal brain development. Genetic or pharmacological disruption of this pathway results in aberrant behaviors.

the re-expression of Casp1 in these cells in Casp1-deficient mice restored normal behaviors (Fig. 2). These results indicate the importance of myeloid cells, particularly microglia, in early brain development to ensure normal behaviors in mice.

The current study shows that microglial lytic cell death occurs in a spatiotemporal manner, with small subsets of microglia in the iTh and LGE undergoing death from E12.5 to E14.5. The timing of microglial death during development is essential since NPCs start to differentiate at E12.5 in the mouse brain. It is also possible that active cell death occurs in NPCs and newly differentiated neurons in and around this timeframe. Thus, dead or dying NPCs and neurons could release ATP and $\mathrm{K}^{+}$that could trigger the NLRP3 cascade in microglia, resulting in the cleavage of
pro-IL1 $\beta$ to its mature form (He et al., 2016). It has been reported that microglial IL-1 $\beta$ is required for NPC differentiation and death (Crampton et al., 2012; Guadagno et al., 2015), so we attempted to measure the amount of secreted IL-1 $\beta$ in the ventricles of the fetal brain by ELISA assay. IL-1 $\beta$ levels were found to be below the level of detection (data not shown), but we assume that this was because only a small number of cells underwent lytic cell death (Extended Data Fig. 3-1B). However, despite the undetectable levels of $\mathrm{IL}-1 \beta$ in the fetal brain, we and another group found that $11-1 r^{-/-}$mice exhibit behavior abnormalities (Murray et al., 2013 and this article), suggesting that IL- $1 \beta$ does indeed play a role in ensuring normal behavior development in mice. 
Since we observed that $\mathrm{Pax}^{+}$NPCs were a part of $\mathrm{PI}^{+} \mathrm{C} \times 3 \mathrm{cr} 1-\mathrm{GFP}^{+}$clusters (Fig. $4 A$ ), and neural circuits are important for behavior, we reasoned that we should look for alterations in neurons as a consequence of defective lytic cell death in Casp $1^{-1-}$ microglia to explain the atypical behaviors observed in our inflammasome pathway knock-out mice. We did not observe global changes in brain structures in the striatum and thalamus descendent from the LGE and iTh (Extended Data Fig. 4-1) in adult Casp $1^{-/}$brains; however, we did confirm increased numbers of neurons in the TRN (Fig. 4B,C), a region descending from the microglial lytic cell death zone observed in developing Casp $1^{-1-}$ mice. Interestingly, a recent report suggested that the TRN regulates a circuit required for attention and hyperactivity (Wells et al., 2016), behavior abnormalities that were observed in Casp $1^{-1-}$ mice (Fig. 1A,B; Extended Data Fig. 1-1B-D). As discussed above, this increase in neurons could have been because of a lack of IL- $1 \beta$ production in microglia that resulted in impaired death and/or differentiation of NPCs. Alternatively, we could speculate that microglial engulfment of NPCs might be decreased since we observed that mRNA expression of Mrc2, a gene known to be involved in phagocytosis, was decreased in Casp $1^{-1-}$ microglia isolated from adult mice (data not shown). However, since we did not observe the deregulation of other genes regulating phagocytosis in Casp $1^{-1-}$ microglia isolated from adult mice, it is difficult to conclude whether this process is actually impaired. Thus, it would be of interest to study the phagocytic activity of microglia in mice deficient for genes regulating the NLRP3-CASP1GSDMD/IL-1 $\beta$ cascade. Furthermore, additional studies are required to determine whether the functions of neurons in the TRN are also altered to explain the behavior abnormalities observed in mice.

Since increased numbers of microglia (microgliosis) are often associated with pathologic conditions, such as neurodegenerative diseases (Lull and Block, 2010; Brück et al., 2016), we expected that defective microglial death would lead to increased microglial cell numbers in regions descendent from the iTh and LGE, thus altering neural functions. However, we did not observe increased numbers of microglia in the TRN. Lytic cell death of microglia was found to occur primarily in the LGE and iTh regions of the brain. Recent reports suggest that microglia might be transcriptionally heterogenous, indicating that specific microglial subsets may exist in different areas in the brain (Li et al., 2019; Masuda et al., 2019). If this is the case, the lytic cell death that we observed may be occurring only in specific subsets of microglia located in these regions. Based on these results, it is clear that specific microglial lytic cell death has an impact on normal brain development; however, the precise mechanism of this regulation and the interplay between specific microglia and NPCs/neurons in the developing brain warrant further study.

Impressively, injection of NLRP3 and CASP1 inhibitors into pregnant WT mice during the time frame of microglial death resulted in behavior abnormalities in their offspring that recapitulated those observed in the NLRP3 pathway knock-out mice. These results suggest that disruption of this pathway during this key developmental window is sufficient to significantly alter normal brain development and behavior. Since the NLRP3-CASP1-GSDMD/IL-1 $\beta$ cascade in microglia is crucial for normal brain development, and either genetic or pharmacological disruption of this pathway can lead to atypical behavior in mice (Fig. 5D), we propose that pro-inflammatory cytokines, such as IL-1 $\beta$, may play essential roles in regulating the differentiation and proliferation of NPCs (Extended Data Fig. 5-1C). Therefore, the numbers and functions of neurons descending from the LGE and iTh may be altered in mice with defects in the NLRP3-CASP1GSDMD/IL-1 $\beta$ cascade, which could contribute to their behavioral phenotypes.

\section{References}

Broz P, Dixit VM (2016) Inflammasomes: mechanism of assembly, regulation and signalling. Nat Rev Immunol 16:407-420.

Brück D, Wenning GK, Stefanova N, Fellner L (2016) Glia and alphasynuclein in neurodegeneration: a complex interaction. Neurobiol Dis 85:262-274.

Cassel SL, Sutterwala FS (2010) Sterile inflammatory responses mediated by the NLRP3 inflammasome. Eur J Immunol 40:607611.

Chung WC, Huang TN, Hsueh YP (2011) Targeted deletion of CASKinteracting nucleosome assembly protein causes higher locomotor and exploratory activities. Neurosignals 19:128-141.

Coll RC, Robertson AAB, Chae JJ, Higgins SC, Muñoz-Planillo R, Inserra MC, Vetter I, Dungan LS, Monks BG, Stutz A, Croker DE, Butler MS, Haneklaus M, Sutton CE, Núñez G, Latz E, Kastner DL, Mills KHG, Masters SL, Schroder K, et al. (2015) A small-molecule inhibitor of the NLRP3 inflammasome for the treatment of inflammatory diseases. Nat Med 21:248-255.

Crampton SJ, Collins LM, Toulouse A, Nolan YM, O'Keeffe GW (2012) Exposure of foetal neural progenitor cells to IL-1 $\beta$ impairs their proliferation and alters their differentiation - a role for maternal inflammation? J Neurochem 120:964-973.

Fink SL, Cookson BT (2005) Apoptosis, pyroptosis, and necrosis: mechanistic description of dead and dying eukaryotic cells. Infect Immun 73:1907-1916.

Fricker M, Tolkovsky AM, Borutaite V, Coleman M, Brown GC (2018) Neuronal cell death. Physiol Rev 98:813-880.

Guadagno J, Swan P, Shaikh R, Cregan SP (2015) Microglia-derived IL-1 $\beta$ triggers p53-mediated cell cycle arrest and apoptosis in neural precursor cells. Cell Death Dis 6:e1779.

Haimon Z, Volaski A, Orthgiess J, Boura-Halfon S, Varol D, Shemer A, Yona S, Zuckerman B, David E, Chappell-Maor L, Bechmann I, Gericke M, Ulitsky I, Jung S (2018) Re-evaluating microglia expression profiles using RiboTag and cell isolation strategies. Nat Immunol 19:636-644.

He Y, Hara H, Núñez G (2016) Mechanism and regulation of NLRP3 inflammasome activation. Trends Biochem Sci 41:1012-1021.

Heneka MT, Kummer MP, Stutz A, Delekate A, Schwartz S, VieiraSaecker A, Griep A, Axt D, Remus A, Tzeng TC, Gelpi E, Halle A, Korte M, Latz E, Golenbock DT (2013) NLRP3 is activated in Alzheimer's disease and contributes to pathology in APP/PS1 mice. Nature 493:674-678.

Heneka MT, McManus RM, Latz E (2018) Inflammasome signalling in brain function and neurodegenerative disease. Nat Rev Neurosci 19:610-621.

Hong S, Dissing-Olesen L, Stevens B (2016) New insights on the role of microglia in synaptic pruning in health and disease. Curr Opin Neurobiol 36:128-134.

Ising C, Venegas C, Zhang S, Scheiblich H, Schmidt SV, VieiraSaecker A, Schwartz S, Albasset S, McManus RM, Tejera D, Griep 
A, Santarelli F, Brosseron F, Opitz S, Stunden J, Merten M, Kayed R, Golenbock DT, Blum D, Latz E, et al. (2019) NLRP3 inflammasome activation drives tau pathology. Nature 575:669-673.

Jiang YH, Pan Y, Zhu L, Landa L, Yoo J, Spencer C, Lorenzo I, Brilliant M, Noebels J, Beaudet AL (2010) Altered ultrasonic vocalization and impaired learning and memory in Angelman syndrome mouse model with a large maternal deletion from Ube3a to Gabrb3. PLoS One 5:e12278.

Jung S, Aliberti J, Graemmel P, Sunshine MJ, Kreutzberg GW, Sher A, Littman DR (2000) Analysis of fractalkine receptor CX(3)CR1 function by targeted deletion and green fluorescent protein reporter gene insertion. Mol Cell Biol 20:4106-4114.

Kayagaki N, Stowe IB, Lee BL, O'Rourke K, Anderson K, Warming S, Cuellar T, Haley B, Roose-Girma M, Phung QT, Liu PS, Lill JR, Li $\mathrm{H}$, Wu J, Kummerfeld S, Zhang J, Lee WP, Snipas SJ, Salvesen GS, Morris LX, et al. (2015) Caspase-11 cleaves gasdermin D for non-canonical inflammasome signalling. Nature 526:666-671.

Komada M, Takao K, Miyakawa T (2008) Elevated plus maze for mice. J Vis Exp. Advance online publication. Retrieved December 22, 2008. doi:10.3791/1088.

Li Q, Cheng Z, Zhou L, Darmanis S, Neff NF, Okamoto J, Gulati G, Bennett ML, Sun LO, Clarke LE, Marschallinger J, Yu G, Quake SR, Wyss-Coray T, Barres BA (2019) Developmental heterogeneity of microglia and brain myeloid cells revealed by deep single-cell RNA sequencing. Neuron 101:207-223.e10.

Lin CW, Hsueh YP (2014) Sarm1, a neuronal inflammatory regulator, controls social interaction, associative memory and cognitive flexibility in mice. Brain Behav Immun 37:142-151.

Lull ME, Block ML (2010) Microglial activation and chronic neurodegeneration. Neurotherapeutics 7:354-365.

Mamik MK, Power C (2017) Inflammasomes in neurological diseases: emerging pathogenic and therapeutic concepts. Brain 140:2273-2285.

Masuda T, Sankowski R, Staszewski O, Böttcher C, Amann L, Sagar, Scheiwe C, Nessler S, Kunz P, van Loo G, Coenen VA, Reinacher PC, Michel A, Sure U, Gold R, Grün D, Priller J, Stadelmann C, Prinz M (2019) Spatial and temporal heterogeneity of mouse and human microglia at single-cell resolution. Nature 566:388-392.

Mizutani M, Pino PA, Saederup N, Charo IF, Ransohoff RM, Cardona AE (2012) The fractalkine receptor but not CCR2 is present on microglia from embryonic development throughout adulthood. J Immunol 188:29-36.

Murray CL, Obiang P, Bannerman D, Cunningham C (2013) Endogenous IL-1 in cognitive function and anxiety: a study in IL1RI-/- mice. PLoS One 8:e78385.

Nakajima R, Takao K, Hattori S, Shoji H, Komiyama NH, Grant SGN, Miyakawa T (2019) Comprehensive behavioral analysis of heterozygous Syngap1 knockout mice. Neuropsychopharmacol Rep 39:223-237.

Oosterhof N, Chang IJ, Karimiani EG, Kuil LE, Jensen DM, Daza R, Young E, Astle L, van der Linde HC, Shivaram GM, Demmers J, Latimer CS, Keene CD, Loter E, Maroofian R, van Ham TJ, Hevner RF, Bennett JT (2019) Homozygous mutations in CSF1R cause a pediatric-onset leukoencephalopathy and can result in congenital absence of microglia. Am J Hum Genet 104:936-947.
Paolicelli RC, Bolasco G, Pagani F, Maggi L, Scianni M, Panzanelli P, Giustetto M, Ferreira TA, Guiducci E, Dumas L, Ragozzino D, Gross CT (2011) Synaptic pruning by microglia is necessary for normal brain development. Science 333:1456-1458.

Ransohoff RM, El Khoury J (2015) Microglia in health and disease. Cold Spring Harb Perspect Biol 8:a020560.

Rathinam VA, Fitzgerald KA (2016) Inflammasome complexes: emerging mechanisms and effector functions. Cell 165:792-800.

Rauch I, Deets KA, Ji DX, von Moltke J, Tenthorey JL, Lee AY, Philip NH, Ayres JS, Brodsky IE, Gronert K, Vance RE (2017) NAIPNLRC4 inflammasomes coordinate intestinal epithelial cell expulsion with eicosanoid and IL-18 release via activation of caspase-1 and -8. Immunity 46:649-659.

Rucklidge JJ (2010) Gender differences in attention-deficit/hyperactivity disorder. Psychiatr Clin North Am 33:357-373.

Saijo K, Glass CK (2011) Microglial cell origin and phenotypes in health and disease. Nat Rev Immunol 11:775-787.

Sanchez-Roige S, Peña-Oliver Y, Stephens DN (2012) Measuring impulsivity in mice: the five-choice serial reaction time task. Psychopharmacology (Berl) 219:253-270.

Shi J, Zhao Y, Wang K, Shi X, Wang Y, Huang H, Zhuang Y, Cai T, Wang F, Shao F (2015) Cleavage of GSDMD by inflammatory caspases determines pyroptotic cell death. Nature 526:660-665.

Shieh KR, Yang SC (2019) Exploratory and agile behaviors with central dopaminergic activities in open field tests in Formosan wood mice (Apodemus semotus). J Exp Biol 222:jeb199356.

Susaki EA, Tainaka K, Perrin D, Kishino F, Tawara T, Watanabe TM, Yokoyama C, Onoe H, Eguchi M, Yamaguchi S, Abe T, Kiyonari H, Shimizu Y, Miyawaki A, Yokota H, Ueda HR (2014) Whole-brain imaging with single-cell resolution using chemical cocktails and computational analysis. Cell 157:726-739.

van der Velden AW, Velasquez M, Starnbach MN (2003) Salmonella rapidly kill dendritic cells via a caspase-1-dependent mechanism. $\mathrm{J}$ Immunol 171:6742-6749.

Voet S, Srinivasan S, Lamkanfi M, van Loo G (2019) Inflammasomes in neuroinflammatory and neurodegenerative diseases. EMBO Mol Med 11:e10248.

Walsh JG, Muruve DA, Power C (2014) Inflammasomes in the CNS. Nat Rev Neurosci 15:84-97.

Watson C, Paxinos G, Puelles L (2012) The mouse nervous system. San Diego: Academic Press.

Wells MF, Wimmer RD, Schmitt LI, Feng G, Halassa MM (2016) Thalamic reticular impairment underlies attention deficit in Ptchd1 (Y/-) mice. Nature 532:58-63.

Wolf SA, Boddeke HW, Kettenmann H (2017) Microglia in physiology and disease. Annu Rev Physiol 79:619-643.

Wolf Y, Yona S, Kim KW, Jung S (2013) Microglia, seen from the CX3CR1 angle. Front Cell Neurosci 7:26.

Yamaguchi Y, Miura M (2015) Programmed cell death in neurodevelopment. Dev Cell 32:478-490.

Yoshida H, Kong YY, Yoshida R, Elia AJ, Hakem A, Hakem R, Penninger JM, Mak TW (1998) Apaf1 is required for mitochondrial pathways of apoptosis and brain development. Cell 94:739-750.

Zhang Y, Chen X, Gueydan C, Han J (2018) Plasma membrane changes during programmed cell deaths. Cell Res 28:9-21. 